\title{
A review of theories of human amnesia
}

\author{
LEONARD D. STERN \\ University of Oregon, Eugene, Oregon 97403
}

\begin{abstract}
Six theories of human amnesia are examined. Each is categorized according to the processing ability that is conceived to underlie the amnesic deficit. The theories fall into one of four categories: consolidation, retrieval, semantic encoding, and context encoding deficit theories. The recently proposed context encoding deficit theories are found to offer the most satisfactory account of the human amnesic syndrome. It is suggested that the other theoretical approaches are best viewed as special cases of these context encoding deficit theories.
\end{abstract}

The human amnesic syndrome is characterized by a severely impaired memory for day-to-day events accompanied by normal intelligence, perceptual abilities, and other cognitive functions. Amnesia is typically associated with brain trauma brought about by blows to the head, surgical removal of portions of the brain, or degenerative processes that accompany excessive and prolonged alcohol consumption (Korsakoff's syndrome).

The focus of this paper will be on theoretical accounts of the human amnesic syndrome. The theories of amnesia to be considered here all use different conceptual grounds to draw a sharp distinction between what amnesics can and cannot do. B. Milner characterizes amnesia as an inability to consolidate information into a stable long-term trace. Weiskrantz and Warrington propose that amnesics are unable to restrain retrieval of inappropriate information. In describing the amnesic deficit, Cermak and Butters stress the division between deep and shallow encoding. Huppert and Piercy postulate that amnesics have a normal item memory but an impaired memory for context. Wickelgren differentiates between horizontal and vertical associative capabilities. And O'Keefe and Nadel base their theory of amnesia on a distinction between a taxon memory system and a locale memory system.

In this paper, these six theories will be summarized, together with relevant evidence. A special effort will be made to resolve major conflicts between the theories. The conclusion to be reached here is that the differences between the theories stem from the use of concepts that permit inappropriate generalizations. These differences are minimized when the theoretical concepts are applied more selectively.

\section{CONSOLIDATION}

In the early 1950 s, Scoville devised a medial temporal. lobe operation that he used as an experimental surgical

I greatly appreciate the comments given by Douglas Hintzman, Daniel Kimble, Michael Posner, and Wayne Wickelgren to a previous version of this paper. Requests for reprints should be addressed to Leonard D. Stern, who is now at the Department of Psychology, Eastern Washington University, Cheney, Washington 99004. technique in the treatment of psychosis. This surgical procedure, used as an alternative to a complete frontal lobotomy, was intended to avoid the side effects that the lobotomy normally produced (B. Milner, 1966). After 30 of these operations had been performed, it was discovered that a serious memory impairment could result. Memory deficits were initially discovered in two of Scoville's patients. One patient had undergone surgery to treat a psychosis, and the other, the well-known H.M., had undergone surgery to control epileptic seizures. In both cases, Scoville's records show that the surgery destroyed the anterior two-thirds of the hippocampus bilaterally, including the uncus and the amygdala (B. Milner, 1970).

On a subsequent examination of eight patients who were well enough to be tested, Scoville and B. Milner (1957) found that the bilateral hippocampal excision had left the patients with a continuous anterograde amnesia (AA) as well as some retrograde amnesia (RA). The severity of these memory disturbances showed a rough positive correlation with the extent of hippocampus and hippocampal gyrus damage (B. Milner, 1966). A more thorough set of tests was given to H.M. 14 years after his operation. H.M. was found to have no postoperative personality change, decline in general intelligence, or deficiency in perceptual processing (B. Milner, Corkin, \& Teuber, 1968). In addition, his digit span (B. Milner, 1966) and short-term memory (Wickelgren, 1968) were in the normal range. However, H.M. appeared to be unable to form new longterm memories. Prisco (cited in B. Milner, 1966) demonstrated this deficit using a delayed paired comparison task. When a 60 -sec interval separated the presentation of two nonverbal auditory or visual stimuli that were to be judged as either the same or different, H.M.'s level of performance fell to chance. Normal subjects perform almost perfectly under these same conditions. Presumably, this task is one that relies heavily on long-term memory, especially after delays of $30 \mathrm{sec}$ or more.

It should be noted that the stimuli used in Prisco's (cited in B. Milner, 1966) task could not be easily verbalized; the stimuli included tones, colors, nonsense figures, and light flashes. A subject could, however, recode such stimuli into a verbal and thus rehearsable form by 
assigning each stimulus a position on some suitable scale. As B. Milner and Teuber (1968) point out, H.M.'s apparent failure to employ this strategy may have been the direct result of his long-term memory deficit. This memory deficit may have made it difficult for him to remember the stimuli long enough to establish the necessary reference scales.

Amnesic long-term memory deficits have also been found using verbal material: When rehearsal was permitted and the material did not exceed his memory span, H.M.'s retention was reported to be normal (Sidman, Stoddard, \& Mohr, 1968); however, H.M. was unable to remember a sequence of digits that exceeded his immediate span by one item, even after the digit sequence had been presented and tested 25 times (Drachman \& Arbit, 1966).

B. Milner et al. (1968, p. 217) give examples of H.M.'s everyday behavior that attest to his inability to form long-term traces: "During three of the nights at the Clinical Research Center, the patient [H.M.] rang for the night nurse, asking her, with many apologies, if she would tell him where he was and how he came to be there. He clearly realized that he was in a hospital but seemed unable to reconstruct any of the events of the previous day. On another occasion he remarked 'Every day is alone in itself, whatever enjoyment I've had, and whatever sorrow I've had.' Our own impression is that many events fade for him long before the day is over. He often volunteers stereotyped descriptions of his own state, by saying that it is 'like waking from a dream.' His experience seems to be that of a person who is just becoming aware of his surroundings without fully comprehending the situation, because he does not remember what went before."

To account for these findings, B. Milner $(1965,1966)$ has proposed that in amnesics, the ability to consolidate information into a stable long-term trace is impaired. According to this explanation, new long-term learning cannot occur, but information can be retained normally in the short-term store.

Müller and Pilzecker (1900) are generally acknowledged to have first articulated the basic premises of consolidation theory. They proposed that a learning trial initiates neural activity that endures for some period of time; this perseverating neural activity, if not interrupted, establishes an increasingly more secure memory trace. Disruption of the perseverating activity interferes with the trace-fixing process and thus leads to memory loss.

Müller and Pilzecker (1900) originally proposed their theory to explain the effects of retroactive interference in verbal learning, that is, to account for the detrimental effect of List 2 learning on List 1 retention. While this use of the consolidation notion has subsequently been replaced by competition theories of forgetting, consolidation hypotheses are still used to explain the phenomenon of experimentally induced RA.
Important evidence in support of this approach has come from experiments showing that retention is greater the longer administration of the amnesic agent is withheld following the learning trial (e.g., Duncan, 1949; Thompson \& Dean, 1955). Arguments against this consolidation account have been based not on an accumulation of experimental data that consistently contradict predictions of a consolidation hypothesis, but rather on the possibility of accounting for the evidence with alternative theories (e.g., Lewis, 1969; Lewis \& Maher, 1965).

B. Milner's $(1965,1966)$ proposal that H.M.'s deficit stemmed from a consolidation defect was in keeping with consolidation accounts of amnesia in animal subjects. The novel aspect of Milner's proposal was the apparently strong association between the hippocampus and the consolidation process. It appeared to Milner and others that "the hippocampus or some other limbic structure in the temporal lobe plays a direct role in consolidation in human beings" (P. Milner, 1970).

H.M.'s unimpaired short-term memory and defective long-term memory is clearly consonant with a consolidation theory. Baddeley and Warrington (1970) have found similar deficits in patients whose amnesias resulted from diverse etiologies, including encephalitis, carbon monoxide poisoning, Korsakoff's psychosis, and a right temporal lobectomy. It should be noted that while recent evidence indicates there are some differences in the amnesias of encephalitic and Korsakoff patients (Mattis \& Kover, 1978), Korsakoff patients are most frequently used in studies of amnesia; four of Baddeley and Warrington's six subjects were diagnosed as alcoholic Korsakoff patients. Thus, what is of greatest concern is the possibility of qualitative differences in the deficits of Korsakoff and temporal-lobe lesioned subjects. The amnesic symptoms of these two classes of patients appear to be similar. In addition, although the neurological evidence for Korsakoff patients is not certain (Kimble, 1975), both subject populations appear to have suffered damage to the hippocampus or to structures such as the thalamic and hypothalamic nuclei, which receive input from the hippocampus (but see Horel, 1978).

Baddeley and Warrington's (1970) conclusion that amnesia is associated with intact short-term memory and defective long-term memory was based on three findings: A Brown-Peterson task revealed no differences in the recall performance of amnesic and control patients for delays of up to $60 \mathrm{sec}$. This was taken to be evidence that the amnesic subjects' short-term memories were unimpaired. A digit-span measure provided further evidence for unimpaired amnesic short-term memory. For strings of up to seven numbers, the digit spans of the amnesic and control groups did not differ. For strings of eight numbers, control subjects recalled $20 \%$ of the strings correctly, but amnesic subjects could not repeat any of the six eight-item strings correctly. 
Baddeley and Warrington suggested that recall of strings of numbers longer than seven items must rely on longterm memory. More direct evidence of an amnesic longterm memory deficit was obtained from serial position data. For 10-item lists of nouns, amnesic subjects recalled fewer items from each of the first eight serial positions than did control subjects. However, recall performance of items from the last two serial positions, which presumably relies on short-term memory rather than on long-term memory, was no different for the amnesic and control subjects.

A number of specific objections have been made to the Baddeley and Warrington (1970) study (e.g., Butters \& Cermak, 1974; Kinsbourne \& Wood, 1975). However, even if these objections were dismissed, the Baddeley and Warrington findings would still not unequivocally support a consolidation theory of amnesia. Rather, as in the case of animal studies, the data may be explained without reference to a consolidation mechanism. First, the data from Baddeley and Warrington's BrownPeterson task do not have much bearing on a consolidation hypothesis because the role of short-term and longterm memory in their version of this task is unclear. Baddeley and Warrington argue that equivalent amnesic and control performance in their Brown-Peterson task is consistent with an impaired amnesic long-term and an intact amnesic short-term memory. A consolidation view would, of course, attribute this amnesic long-term memory deficit to difficulties in establishing stable long-term traces from short-term traces. However, given this assessment of amnesia, one could reasonably expect amnesic performance to differ from that of control subjects in a Brown-Peterson task. That is, according to two-process memory theorists, after intervals as short as $6 \mathrm{sec}$ (Peterson, 1966) or even $3 \mathrm{sec}$ (Dillon \& Reid, 1969), performance in a Brown-Peterson task already may reflect some effect of long-term memory; thus an amnesic deficit after the $60 \mathrm{sec}$ of distractor activity employed in the Baddeley and Warrington study would certainly be in keeping with a consolidation view. In any case, the possibility that amnesic subjects rely more on phonetic encodings than do normal subjects (Cermak \& Butters, 1973) makes interpretation of these data difficult: Since phonetically encoded traces are more susceptible to interference than are semantically encoded traces (Wickelgren, 1973), differences in performance on a Brown-Peterson task may refiect differences in encodings rather than in the functioning of the memory stores.

The use of different encoding strategies by the normal and amnesic groups may also have contributed to differences found in their serial position curves. It has been suggested that different processing strategies are typically applied to recency and prerecency items in a free recall list (Craik \& Watkins, 1973; Watkins \& Watkins, 1974), with elaborative encoding generally performed on early items and maintenance of Type $\mathbf{I}$ processing applied to the last few list items (Craik \&
Lockhart, 1972). If amnesic subjects do prefer surface rather than deep encodings, and if surface cues, such as acoustic properties, are effective only for more recent items (Tulving, 1968), then the amnesic prerecency deficit can be accounted for without a consolidation theory.

Finally, support for a consolidation theory based on amnesic digit-span performance can be questioned. Baddeley and Warrington (1970) wish to argue that a normal digit span, that is, normal recall of strings of up to seven digits, indicates an intact short-term memory; deficient recall performance of eight-digit strings indicates a long-term memory deficit. A problem with these assumptions, however, is that there is no good evidence for a correlation between digit span and either short-term or long-term memory performance. Martin (1978) has found nonsignificant correlations between digit span and immediate or delayed free recall performance of 12-word lists. Furthermore, each of four different estimates of primary memory capacity and three estimates of secondary memory performance also failed to correlate significantly with digit span. Since Martin's data show that digit span correlated with the ability to maintain the temporal order of information in memory, an amnesic deficit in maintaining order information may underlie the amnesic deficit found in the Baddeley and Warrington digit-span experiment. Encoding deficits may, again, offer a suitable alternative to a consolidation theory in accounting for this impairment.

While the imprecision of the consolidation approach allows alternative interpretations to be given to experimental findings, this imprecision also gives consolidation a flexibility that has made it quite resilient. For example, Corkin (1968) has shown that H.M. is capable of near normal long-term learning in some motor tasks. This potentially troubling finding can be reconciled with a consolidation view by suggesting that consolidation mediated by the hippocampus is not involved in motor learning (B. Milner, 1970).

For another example of this flexibility, consider the evidence concerning RA. It is well known that, except for a variable period of time that antedates the occurrence of the amnesia-inducing event, the period of RA, memory for remote events is normal. Amnesics are capable of using language normally and appear to vividly recall many events that occurred before the onset of their illness. H.M., for instance, seemed to show normal memory for events that had occurred up to 2 years before his operation (B. Milner et al., 1968). Similarly, Talland (1965) reports that his chronic Korsakoff patients, although varying considerably in the extent of their RA, had no trouble retrieving memories of events that had occurred much earlier in their lives. In general, these findings that RA affects recent memories rather than older memories are in accord with a consolidation hypothesis, for a pure consolidation expla- 
nation of RA has the amnesic agent interrupting the perseverating neural activity that is responsible for the buildup of the long-term trace. Thus, this hypothesis predicts a temporally graded effect: Oldest memories will be less susceptible to disruption than will recent memories because the oldest memories will have experienced the most neural activity and thus will be the least fragile.

A problem is raised for consolidation theories, however, by the relatively long duration of human RA. Although Russell and Nathan (1946) report that, in the majority of accidental head injury cases, RA lasts "a few moments only" (in 840 of the 1,029 cases they report, RA lasted less than $30 \mathrm{~min}$ ), others have claimed that RA can extend back for months, years (Warrington \& Sanders, 1971), or even a person's whole life (Warrington \& Weiskrantz, 1973). These claims raise difficulties for a consolidation approach, for RA cannot be attributed to a consolidation deficit if the amnesia extends beyond the time that the short-term trace can be assumed to be active. In dealing with this problem, Deutsch and Deutsch (1966) have suggested that the long duration of RA might simply mean that there are two consolidation processes, one for short-term traces and another for long-term traces. Presumably, amnesic agents that produce long-duration RA have disrupted not only short-term consolidation, but long-term consolidation as well.

It is possible to dismiss a number of findings that are problematical for a consolidation view by attributing them to other causes. For example, in both humans and animals, some recovery from RA can occur (e.g., Lewis, Misanin, \& Miller, 1968); this is not predicted by most consolidation theories, since any memory impairment arising from a disruption of the consolidation process should be permanent. In humans, a memory recovery phenomenon known as "shrinking RA" is most commonly observed as a side effect of electroconvulsive therapy or brain concussion. On the basis of the cases they have observed, Russell and Nathan (1946, p. 292) report that "during this period of shrinking amnesia the patient is unable to recall an important group of memories which, as later recovery shows, were well registered. The recovery occurs not in order of importance but in order of time. Long-past memories are the first to return, and the temporary blocking of relatively recent memory may be so marked that several years of recent life may be entirely eliminated." To account for shrinking RA, Deutsch and Deutsch (1966) propose that the amnesic agent not only disrupts consolidation but also superimposes some change on the memory system that prevents access to the partially consolidated memory trace. This additional change is suggested to be reversible, so memory can return. In the following passage, they use the term "memory change" to refer to the product of the consolidation process. "As a result of injury or disease, another change occurs which makes it impossible to utilize a certain fixed amount of the memory change. If the accumulated memory change is large, a greater change due to injury or disease is necessary to counteract its normal function. Such a view would account both for the retrograde character of some amnesias-that is, the fact that the gap in memory extends back from the time of the injury-and also for the fact that recovery of memory is also possible" (Deutsch \& Deutsch, 1966, pp. 74-75).

While it is likely that amnesic agents have a wide range of effects on the memory system, a theory becomes less attractive the more its applicability is restricted and the more other explanatory devices have to be invoked. As will be discussed in the next section, the domain of a consolidation explanation of amnesia is further curtailed by the discovery of residual long-term memory capabilities in amnesic patients.

\section{RETRIEVAL}

It would be unwise to attribute the general acceptance of any one theory of amnesia to evidence gathered solely from experimental investigations of amnesia itself. Rather, the status of a theoretical mechanism or explanatory concept in the psychological literature as a whole must be considered. Beginning with McGeoch's (1942) response-competition theory, consolidation has been invoked less often to explain normal human forgetting and the popularity of interference theories has grown. Thus, the emphasis has shifted from forgetting as an unavailability of memories to forgetting as a failure to retrieve potentially accessible traces. In light of this growing popularity of the theoretical importance of retrieval processes, the recent proliferation of investigations of amnesia based on retrieval failure hypotheses should not be surprising.

Much of the work that has been used to support a retrieval explanation of human amnesia has been done by Weiskrantz and Warrington. An early study (Weiskrantz \& Warrington, 1970a) demonstrated that after a 3-day interval, amnesic subjects showed "significant savings" in their retention of eight five-letter words. To obtain these results, however, an unconventional learning and testing procedure had to be devised. The procedure used was based on a technique originally reported by Williams (1953) and later successfully demonstrated by Warrington and Weiskrantz (1968). This procedure will be referred to as the partial stimulus method. The exact details of this procedure as used by Weiskrantz and Warrington (1970a) are as follows: Three photographic versions were made of each of eight common English words. Patchwork filters were used to randomly exclude small rectangular areas from each photograph. These rectangular areas amounted to $0 \%$, $50 \%$, or $80 \%$ of the total area photographed. Six amnesic and six control patients were shown the eight words in their most degraded form and asked to guess the name of the word being shown. If a word was not correctly identified, successively more complete versions of the 
word were presented. Word sets were repeated until all stimuli could be recognized in their most incomplete form. Each subject served in three experimental sessions; one of three different sets of words was presented in each session. The sessions differed in that the retention interval was $1 \mathrm{~h}, 24 \mathrm{~h}$, or $72 \mathrm{~h}$. After each retention interval, subjects relearned the eight words to a criterion of two errorless trials.

The amnesic and control patients did not differ in their ability to identify the words after seeing them for the first time in either the $80 \%$ or the $50 \%$ degraded form. Thus, their "perceptual" abilities were equivalent. However, the amnesics took significantly more trials to learn the words, and their savings scores at the 1-, 24-, and $72 \cdot \mathrm{h}$ intervals combined were significantly lower than were the control group's scores. Although these results do not contradict any predictions that could be made by a consolidation hypothesis, further analysis of the data showed that at all retention intervals, amnesic patients showed significant savings. Weiskrantz and Warrington concluded that their data indicate there was "a relatively slow decline in patients' retention compared with clinical impressions and more conventional testing methods" (1970a, p. 286).

One implication of these data, then, is that amnesic patients are capable of some retention of verbal information over long periods of time. Prior to these studies by Weiskrantz and Warrington, the only other long-term learning that amnesic patients had demonstrated was motor learning. B. Milner (1962, cited in B. Milner, 1970) had shown that H.M. was capable of improving his performance on a mirror drawing task. According to Milner, H.M.'s learning curve over a 3-day period was normal, with performance at each new session beginning at the level reached by the end of the previous day's training. Corkin (1968) later extended Milner's findings to other motor tasks. Milner (1970) has reconciled these findings with her consolidation hypothesis by specifying that the acquisition of motor skills is not mediated by the hippocampus.

The initial findings of Weiskrantz and Warrington (1970a) could be dismissed in a similar way. One could propose that the partial stimulus method relies on a form of perceptual learning in which the subject acquires an ability to perceive a particular letter when shown its degraded version and that this kind of perceptual learning takes place independently of the hippocampal system (B. Milner, 1968). However, Weiskrantz and Warrington have carried out much additional research from which a quite different conclusion has been drawn. In an experiment similar to the one described above (Weiskrantz \& Warrington, 1970b), fragmented words were replaced by either the first two letters or the first three letters of five-letter words. The results of this follow-up study were like those of the previous experiment. Weiskrantz and Warrington claim that presenting the first two or three letters of a word places no "per- ceptual strain" on a subject; thus, they argue that the explanation offered by Milner can be rejected. Weiskrantz and Warrington suggest, instead, that because the information was available to their amnesic subjects after long retention intervals, consolidation of information of verbal items is "more nearly normal than has been commonly assumed" (1970b, p. 211).

Warrington and Weiskrantz (1970) have determined that the partial stimulus technique benefits amnesic performance during retrieval, not learning. This, they have suggested, indicates that amnesics differ from normals in the extent to which control over information in storage is altered rather than in terms of consolidation capabilities. Warrington and Weiskrantz propose that the amnesics' defective control over stored items causes them to retrieve too much information; thus, amnesic memory performance suffers because the amnesics are more susceptible to interference than are normals. Warrington and Weiskrantz suggest that cues greatly aid amnesic performance by reducing the number of available response alternatives.

To more thoroughly test their hypothesis, Warrington and Weiskrantz (1974) varied the extent to which a retrieval cue limited the number of response alternatives. If amnesic subjects are particularly susceptible to intrusions from previously learned items, cues that narrow the range of response alternatives should differentially aid their performance. Retention of 10 -word lists was tested with the first three letters of the to-berecalled words, after a $60-\mathrm{sec}$ filled interval. Amnesic subjects were found to benefit more than control subjects if the cues could apply to 4-6 alternative English words rather than to 10 or more alternative words. Although Weiskrantz and Warrington have used these data to conclude that "amnesic subjects were helped relatively more by the cues to the narrow set than to the wide set" (1975, p. 415), it should be noted that the Groups by Conditions interaction was not significant $(p<.1)$ and, because control performance was higher overall than amnesic performance (control performance ranged from approximately $78 \%$ to $85 \%$ correct, whereas the corresponding range for amnesic subjects was $62 \%$ to $78 \%$ ), a ceiling effect might have masked the tendency of the control group to have been equally affected by the range of the response-cue alternatives.

Another method of constraining response alternatives was used by Winocur and Weiskrantz (1976) to further test the hypothesis. Five amnesic subjects were presented either 12 semantically related paired associates (Experiment 1) or 12 rhyming paired associates (Experiment 2). Although the amnesic subjects were unable to learn unrelated pairs when given four exposures to 12-item lists (Experiment 4), they learned the semantically related pairs and the rhyming pairs as effectively as did the control subjects. This can be taken to support the Weiskrantz and Warrington (1970a, 1970b) retrieval hypothesis if it is assumed that the consistent use of 
semantic or rhyme characteristics to relate word pairs allowed subjects to generate appropriate rules, which they used to limit the number of acceptable responses.

In addition to examining first-list learning, Winocur and Weiskrantz (1976) also investigated second-list learning. Thirty minutes after subjects were shown a list of semantically related paired associates, they were presented a second paired association list composed of List 1 stimulus terms paired with new semantically related response words. As expected, normal subjects learned List 2 significantly better than did amnesic subjects. In fact, amnesic subjects showed no appreciable learning of List 2 . More to the point, however, intrusions from List 1 constituted a significantly higher percent of the total errors for amnesic subjects (70\% when List 1 had been repeated four times) than for control subjects $(32 \%)$. Similar results were found when the stimulus and response words in Lists 1 and 2 were related on the basis of their rhyming characteristics. These results indicated to Winocur and Weiskrantz that the basic impairment of their amnesic subjects was not that they were unable to consolidate information, but that they were unable to retrieve the appropriate information from long-term memory.

To determine whether using a different rule to relate a stimulus word to its response term in two successive lists reduced the number of List 1 intrusions during List 2 learning, Winocur and Weiskrantz (1976) paired words in the first list on the basis of meaning and paired words in the second list on the basis of rhyme. Although their second-list performance was not as good as that of controls, amnesic subjects were able to learn the list; the amnesic group made significantly fewer errors on List 2 when List 1 was based on a rhyme rule rather than on a semantic rule. Winocur and Weiskrantz (1976) judged these results to be consistent with the retrieval hypothesis: An altered learning context, serving as a retrieval cue, aided amnesic performance by limiting the availability of interfering responses.

The retrieval theory has been extended to other phenomena that characterize the amnesic syndrome. Warrington and Weiskrantz (1970) suggest that motor learning is normal in amnesic patients because motor skills, in general, are unaffected by interference. The finding that recognition memory is impaired in amnesic subjects has been dealt with by suggesting that recognition is probably mediated by associative retrieval mechanisms (Warrington, 1974); thus, recognition, like recall, is subject to interference. In order to account for RA in terms of a general retrieval failure, Warrington and Weiskrantz (1973) suggest that the duration of RA has been underestimated. They propose that memory deficits may actually extend back to encompass an amnesic's entire existence. Citing findings of Warrington and Sanders (1971) that showed that remote memories in older subjects (aged 70-79 years) were not selectively preserved relative to recent memories, Warrington and
Weiskrantz conclude that "a unitary functional disorder could account for both retrograde and anteograde effects in the amnesic syndrome" (1973, p. 376).

This optimism may have been premature. A recently published series of studies by Warrington and Weiskrantz (1978) has produced evidence inconsistent with their retrieval theory. One source of disturbing evidence came from an experiment modeled after the modified-modified free recall paradigm. Subjects were shown two lists of 15 words. For each word in List 1 , there was a word in List 2 that shared the same first three letters. Although the three initial letters of each word pair matched 10 or more alternative English words, only the two lowest frequency responses generated by an independent group of subjects in response to the letter cues were used in the experiment. List 1 words were presented at a 2-sec rate. Retention was tested immediately after list presentation by prompting subjects with the three-letter cues. After a 15-min filled interval, subjects were shown the second list. The three initial letters of each stimulus word were then presented, and subjects were asked to provide the appropriate List 1 and List 2 words in any order. Performance of the amnesic and control subjects did not differ significantly in original List 1 retention or in retention of Lists 1 and 2 measured after List 2 learning.

Warrington and Weiskrantz (1978) did not find support for their retrieval theory in these results. According to their hypothesis, amnesic subjects are highly susceptible to intrusions from previous learning. Thus, Warrington and Weiskrantz expected that List 1 items would be more available to amnesics than to control subjects after List 2 learning. The data failed to verify this prediction.

Evidence that Warrington and Weiskrantz (1978) regarded as more damaging to their retrieval view was obtained from a reversal learning task. The word pairs that functioned as stimuli in this experiment were the only ones in a dictionary of basic English that shared their first three letters (e.g., cyclone, cycle). Fifteen word pairs were presented in two study lists; the pair member that had been emitted more frequently by a group of normal subjects in response to a three-letter cue was assigned to List 1 . Amnesic and control subjects were instructed to read the words in List 1 aloud as each word was presented. Retention was tested immediately after List 1 presentation by cuing subjects with the first three letters of each word. List 2 words were then presented and tested in a similar way. This study-test sequence was repeated four times for List 2 . The results showed that, while amnesic subjects did not learn List 2 as well as did control subjects when performance was collapsed over the four learning trials, there was little difference between amnesic and control performance after the first List 2 study trial. If amnesic subjects were, in fact, differentially affected by interference from prior learning, the List 1 items should 
- have provided their maximum interference on the first List 2 learning trial, since at this point in the experiment, List 1 items would have been most available. On the basis of their most recent evidence, Warrington and Weiskrantz (1978, p. 175) drew the following conclusion: "The most significant outcome of this series of experiments was the failure to find significant heightened interference effects in amnesic subjects on the first occasion on which the interfering effects of prior learning could be revealed. The important change in amnesic performance occurred between the first and second reversal trials. Even though the amnesic subjects failed to learn the second list with repeated trials, they did not show a significantly enhanced decrement on the first trial. While there may be trends in its favour, the hypothesis that cued recall methods derive their beneficial effect by reducing response competition does not receive the strong support that the hypothesis demands."

A fundamental assumption of the Weiskrantz and Warrington (1970a) hypothesis is that amnesic subjects acquire information normally. This makes comparison of amnesic and control performance relatively uncomplicated. However, as the following discussions will show, this assumption may not be correct.

\section{SEMANTIC ENCODING}

Cermak and Butters (1973) have proposed that amnesic patients have severe short-term memory deficits. Supporting evidence has been obtained by Cermak, Butters, and Goodglass (1971), using a Brown-Peterson task. The stimuli were consonant trigrams, single highfrequency three-letter words, and triads of three-letter high-frequency words. The performance of Korsakoff patients was consistently poorer than that of control subjects at retention intervals of 9 and $18 \mathrm{sec}$, but not at 0 sec. This finding is in direct opposition to that of Baddeley and Warrington (1970), who had shown no difference between amnesics and controls even at retention intervals of up to $60 \mathrm{sec}$. Butters and Cermak (1974) suggested two accounts of this discrepancy: (1) Subjects in the Baddeley and Warrington study may have rehearsed during the retention interval, since the standard backward counting by threes procedure had been modified by Baddeley and Warrington to an unpaced backward counting by ones task; (2) Baddeley and Warrington's subjects may not have been as severely amnesic as were the patients used by Cermak et al. (1971).

Cermak and his co-workers subsequently investigated two factors that could account for this short-term memory deficit in amnesic subjects. One possibility was that amnesics are more susceptible to proactive interference (PI) than are normals. This was confirmed (Cermak \& Butters, 1972) in a study using a Brown-Peterson task. PI was manipulated by varying the similarity of the stimulus material used in two successive trials. Either consonant triads were presented on Trial 1 and word triads on Trial 2 (low-PI condition) or word triads were presented on both trials (high-PI condition). As PI increased, Korsakoff patients exhibited a significantly greater recall decrement than did controls: After $9 \mathrm{sec}$ of distraction, recall dropped $52 \%$ for the amnesic patients vs. $23 \%$ for the control patients; after $18 \mathrm{sec}$, amnesic performance decreased $40 \%$, whereas control performance decreased $14 \%$.

These results are in accord with the retrieval hypothesis of Weiskrantz and Warrington (1970a). However, as a consequence of investigating another possible factor underlying the amnesic short-term memory deficit-the role of encoding-Cermak and his co-workers have arrived at a hypothesis that is somewhat different from the Weiskrantz and Warrington view. The hypothesis is that amnesic subjects do not encode semantic information adequately.

An early indication of this amnesic semantic encoding deficit came from a study that examined cued recall performance (Cermak \& Butters, 1972). Amnesic and control subjects were read two lists of eight words at a 1 -sec rate. The words had been drawn from four categories; both lists contained two words from each category. After subjects had heard List 1, they were instructed to free recall the words. Following a 5-min interval, subjects were told that the words in a second list would come from the same four categories that had been used in the previous list. Subjects were also informed that recall would be cued by category names. The data showed that, relative to free recall performance on List 1 , cuing increased control subjects' List 2 performance but decreased amnesics' performance. Cermak and Butters concluded that the encoding used by the amnesic group was not precise enough to permit retrieval on the basis of categorical information. It was suggested that these amnesic subjects relied more on auditory coding.

Interpreting the data from this experiment may be more problematical than Cermak and Butters (1972) admit. Given the susceptibility of amnesic patients to intrusions from stimuli learned previously, even days before (Warrington \& Weiskrantz, 1968), it is not surprising that the amnesic subjects did not learn the second list as effectively as they had learned the first. This susceptibility to intrusion errors may have been further aggravated by the use of identical categories in the two lists. Since intrusion errors were not reported and since other measures that may have supported an encoding hypothesis (e.g., clustering measures) were not given, these data offer only marginal support for the semantic encoding deficit hypothesis.

More definitive evidence for an encoding hypothesis was obtained from an experiment that measured false recognitions (Cermak, Butters, \& Gerrein, 1973). The task required that subjects read a long list of words and detect the presence of repeated words. Because the list contained words that were acoustically identical to (e.g., the homonyms "bear" and "bare"), strongly associated with, or synonymous with a preceding word, it was possible to estimate subjects' encoding preferences. Amnesics made significantly more homonym and associ- 
ate errors than did controls, but they performed comparably on synonym and neutral words. The two groups did not differ in their detection of repetitions. These results appeared to indicate that the amnesic Korsakoff patients "were encoding the words on acoustic and associative dimensions but were not encoding the semantic dimensions of the words to the extent that would allow the rejection of acoustically identical or highly associated words" (Butters \& Cermak, 1975, p. 393).

This reliance by amnesics on what Cermak, Butters, and Moreines (1974) term the more readily analyzable dimensions of encoding has been seen by Cermak and his co-workers as being the fundamental cause for the great susceptibility of amnesics to PI. That is, because information encoded at "surface" rather than "deep" levels is more susceptible to interference, amnesic subjects may not perform as well as controls. Cermak et al. (1974) have further examined this possibility using a releasefrom-PI paradigm. In this paradigm, a switch in the properties of the to-be-remembered items after PI has built up causes an immediate improvement in memory performance by allowing unique retrieval cues to access the novel information. Of course, retrieval can be successful only if some novel information about the stimulus has been encoded. Cermak et al. expected that amnesics would show normal release from PI with two sets of verbal materials discriminable on the basis of rudimentary categorizations (e.g., letters vs. numbers), but not with stimuli that differed along more abstract semantic lines. These predictions were confirmed: Using number and letter triads as the two classes of stimulus material, amnesic and normal subjects both showed a significant release from PI. However, when the basis of the shift in stimulus material was taxonomic categories (vegetables, animals, tools, or articles of clothing), control subjects showed a release from PI and amnesic subjects did not. Thus, the possibility of a link between susceptibility to PI and a deficit in semantic encoding in amnesics was supported (but see Kinsbourne \& Wood, 1975).

Several points must be made relating to the generality of the conclusions drawn by Cermak and his co-workers. First, it has been found (Cermak et al., 1973; Warrington \& Weiskrantz, 1971) that for amnesic subjects, recall cued by category names can be better than free recall if retention is tested after delays of $1 \mathrm{~min}$ or more. Cermak et al. (1974) have admitted that if the task demands it, amnesic subjects can encode information on semantic dimensions, although less completely than do control subjects, and can use this information to improve retention after a 1-min delay. However, they suggest that when not induced to encode semantically, amnesic subjects rely more on acoustic encoding. Thus, this semantic encoding impairment is perhaps not as profound as might have been inferred.
Another point is that recent evidence calls into question a prediction made on the basis of the semantic encoding theory. Butters, Lewis, Cermak, and Goodglass (1973) proposed that information not stored with the aid of semantic categorizations should be retained equally well by amnesic and control subjects. This prediction, which is just an extension of the semantic encoding deficit hypothesis, was tested using visual, auditory, and tactile versions of a verbal and nonverbal shortterm memory task. In this task, subjects were presented a stimulus and, after 0,9 , or $18 \mathrm{sec}$ of backward counting, were shown a test stimulus to which they were to respond "same" or "different." The results showed that the performance of amnesics was, in general, normal for nonverbal materials, but severely impaired for verbal materials. It is important to note, however, that the same distractor task, counting backward from 100 by twos, was used in all conditions of this experiment. Because more interference is produced when a distractor task is performed in the same modality as the experimental task (L. Brooks, 1968), the results offered by Butters et al. should not be taken as providing clear support for their hypothesis. In fact, recent evidence obtained by Strauss and Butler (1978) indicates that the memory deficit of amnesic Korsakoff patients extends to nonverbal as well as verbal materials.

Finally, it must be emphasized that Cermak and his co-workers attribute the long-term memory deficits of amnesics to defective semantic encoding abilities; that is, they assume that "as a consequence of this encoding deficit, the Korsakoff patient is highly sensitive to proactive interference and manifests great difficulty in the retention of verbal materials" (Butters \& Cermak, 1975 , p. 407). While there is evidence that semantic encoding in general leads to improved long-term retention (e.g., Craik \& Tulving, 1975), there is little in the research findings of Cermak and his co-workers to support a claim for a causal link between amnesics' semantic processing deficits and their profound memory impairments. Furthermore, given the assertion of Cermak and co-workers that under certain conditions amnesics are capable of semantic encoding, it should be possible to decrease the amnesic memory impairment simply by inducing a patient to process to-be-recalled material semantically. That such a possibility is unlikely is suggested by the following incident related by $B$. Milner (1970, p. 37): "He [H.M.] was able to retain the number 584 for at least 15 minutes, by continuously working out elaborate mnemonic schemes. When asked how he had been able to retain the number for so long, he replied: 'It's easy. You just remember 8. You see, 5,8 , and 4 add to 17 . You remember 8 , subtract it from 17 and it leaves 9. Divide 9 in half and you get 5 and 4 , and there you are: 584. Easy.' A minute or so later, H.M. was unable to recall either the number 584 or any of the associated complex train of thought; in fact, he 
did not know that he had been given a number to remember because, in the meantime, the examiner had introduced a new topic."

\section{CONTEXT ENCODING THEORIES}

Brief mention will be made of some conclusions derived from studies of amnesia in animals, for these conclusions have affected the course of work done with human subjects. Experimentally induced hippocampal damage has, in general, not supported the consolidation hypothesis, in that hippocampal animals can display long-term retention of postoperatively acquired behaviors. For example, Orbach, B. Milner, and Rasmussen (1960), using a delayed response task, found no performance deficit in hippocampal monkeys even when a distraction was inserted into the delay period. In this delayed-response task, the animal is permitted to observe which of two wells is being filled with food; the wells are then covered, and after a delay the animal is allowed to access one of the wells to obtain the food.

There is much evidence that bilateral hippocampal destruction produces no apparent long-term memory loss in animals (Isaacson, 1972). This contradiction between animal and human data has, in the recent past, been dealt with in a variety of ways. One approach has been to consider the possibility that the same structure has not been damaged in man and animals (Horel, 1978). Another approach, one that was adopted by Weiskrantz and Warrington in 1967, was to assume that the discrepancy was due to the use of inappropriate methods of testing human retention (Weiskrantz, 1977). It was from this perspective that the partial stimulus technique was conceived.

The conclusion that Weiskrantz and Warrington (1970a, 1970b) drew from the partial stimulus procedure was that amnesics are capable of normal or near-normal long-term retention of verbal material. However, the view taken in this paper is that the data generated by this cuing procedure do not demonstrate learning of the sort that is usually demonstrated by other testing methods. A series of studies by Huppert and Piercy $(1976,1978)$ provides data relevant to this view.

\section{Huppert and Piercy's Theory}

Huppert and Piercy (1976) presented subjects with an 80-item list made up of high- and low-frequency words. In a yes-no recognition test given $10 \mathrm{~min}, 1$ week, and 7 weeks later, it was found that "Korsakoff patients say 'yes' to almost all the high frequency words" (Huppert \& Piercy, 1976, p. 9) regardless of whether the words have been included in the stimulus list or not (see Table 1).

Huppert and Piercy (1976) accounted for these data by suggesting that there are two decision processes used in making recognition judgments. One process, a familiarity judgment, is used to decide whether or not the test item had been encountered before. The second pro-
Table 1

Probability of Hits and False Alarms as a Function of Word Frequency for Amnesic and Control Subjects

\begin{tabular}{|c|c|c|c|c|c|}
\hline \multirow{3}{*}{$\begin{array}{l}\text { Retention } \\
\text { Interval }\end{array}$} & \multirow[b]{3}{*}{ Group } & \multicolumn{4}{|c|}{ Word Frequency } \\
\hline & & \multicolumn{2}{|c|}{ High } & \multicolumn{2}{|c|}{ Low } \\
\hline & & $\mathrm{p}($ Hit $)$ & $\mathrm{p}(\mathrm{FA})$ & $\mathrm{p}$ (Hit) & $\mathrm{p}(\mathrm{FA})$ \\
\hline \multirow{2}{*}{$10 \mathrm{Min}$} & Amnesic & .87 & .58 & .70 & .30 \\
\hline & Control & .75 & .29 & .85 & .10 \\
\hline \multirow{2}{*}{1 Week } & Amnesic & .80 & .66 & .74 & .35 \\
\hline & Control & .92 & .41 & .81 & .19 \\
\hline \multirow{2}{*}{7 Weeks } & Amnesic & .77 & .77 & .67 & .43 \\
\hline & Control & .74 & .53 & .78 & .30 \\
\hline
\end{tabular}

Note-Data are derived from Figures 1 and 2 in Huppert and Piercy (1976).

cess requires a list-membership judgment: The subject decides whether or not the test item was presented in a particular context. Huppert and Piercy proposed that adequate recognition performance for material with which the subject was unfamiliar prior to the experiment could be based on only a familiarity judgment. That is, in a yes-no recognition task, a subject who accepted test items that were familiar and rejected those that were not would be performing perfectly if the old test items had been made familiar only because of their presence in the study list and if the distractors were all unfamiliar. This familiarity judgment strategy, however, would not work for stimuli with which the subject had had extensive preexperimental experience. Under these circumstances, a subject would have to make use of context in order to perform satisfactorily.

To further examine the amnesic deficit in judging the context in which a remembered event was encountered, Huppert and Piercy (1976) familiarized subjects with a set of 80 pictures by presenting the picture list three times on the 1st day of an experiment. On Day 2 , subjects were shown 40 of these familiar and 40 unfamiliar pictures. Ten minutes later, recognition memory for the pictures presented on Day 2 was tested using either a two-choice or a yes-no procedure. In the yes-no test, subjects were first asked whether or not they had seen the picture on Day 2; if their answer was negative, they had to decide whether they had ever seen the picture before. The data showed that in response to the first question, distractor familiarity had a greater adverse effect on amnesic than on control subjects' performance. Whereas control subjects had a false alarm rate of $1.3 \%$ for new distractors and $3.1 \%$ for distractors presented only on Day 1 , the amnesic false alarm rates were $10 \%$ and $50.6 \%$, respectively. Furthermore, for items presented only on Day 1 (the familiar distractors) or Day 2, amnesic subjects responded "yes" to $50.6 \%$ of the familiar distractors and $70 \%$ of the Day 2 pictures; the control data were $3.1 \%$ and $89.4 \%$, respectively. These judgments, given in response to the question "Did you see this picture today?" (i.e., on Day 2), reveal that even though the familiar distractors had been 
shown $24 \mathrm{~h}$ before and the Day 2 items $10 \mathrm{~min}$ before, amnesics were quite poor at discriminating between the two picture sets.

Although amnesic subjects were deficient at discriminating pictures according to their temporal presentation context, amnesics made very few errors in answering the question "Have you seen this picture before?" Performance of amnesic and control subjects in response to this question was close to the ceiling. Huppert and Piercy (1976) see this as support for their claim that item memory is intact in amnesics but context memory is impaired.

For the two-choice recognition test, pictures that had been shown on both days of the experiment were paired with pictures shown only on the 1st day (familiar pairs), and pictures shown only on Day 2 were paired with new pictures (unfamiliar pairs). In selecting Day 2 pictures, control performance was $100 \%$ correct for both familiar and unfamiliar pairs; the amnesics were correct on $87 \%$ of the unfamiliar pairs and $77.5 \%$ of the familiar pairs. The finding that amnesics could perform above chance on the familiar pairs led Huppert and Piercy (1978) to subsequently investigate the basis for this residual capacity to judge recency.

Huppert and Piercy (1978) suggested that estimates of recency of presentation may have been based on three types of information: directly encoded temporal information, frequency information, and trace strength. To distinguish among these possibilities, amnesic and control subjects were shown a different set of pictures on each of 2 consecutive days. In each picture set, 40 items were shown once and 40 were shown three times. At least eight pictures intervened between the repeated items. On Day 2, $10 \mathrm{~min}$ after presentation of the slide list, subjects were shown 80 test pictures; 20 items tested each frequency condition in each of the two experimental picture sets. Subjects were told to indicate the day that they recalled having seen each test picture and whether the picture had been shown once or three times.

Huppert and Piercy (1978) first examined the recency judgments and attempted to determine whether these decisions were based on either trace strength or recency information. The data showed that, in accord with a strength hypothesis, amnesics judged the Day 2 Frequency 3 items to be most recent and the Day 1 Frequency 1 items least recent. Furthermore, amnesics could not distinguish between items presented three times the previous day and those presented once the second day. Control performance, on the other hand, was affected more by day of presentation than by frequency of presentation. Thus, it appeared that control performance, unlike amnesic performance, was not determined solely by trace strength.

For the frequency estimation task, it was expected that responses based only on frequency information would be unaffected by recency of presentation. The amnesic data, however, showed that, as in the recency judgment task, Day 2 Frequency 3 items were rated most frequent and Day 1 Frequency 1 items were rated least frequent. The Day 1 Frequency 3 items and the Day 2 Frequency 1 items received intermediate ratings. These data are, again, in accord with a trace-strength hypothesis. The control data showed an effect of both recency and frequency; however, the control performance was less affected by recency than was amnesic performance. Huppert and Piercy (1978, pp. 332-333) came to the following conclusion: "We hypothesize that each presentation of an item normally results in both a multi-attribute encoding of that item and an increment in its trace strength. We further suggest that individual attributes fade more rapidly than overall trace strength, so that when information about an attribute which contributes to trace strength is no longer available, judgments are made on the basis of overall trace strength." Because amnesic performance appears to have been based principally on trace strength, the claim can reasonably be made that amnesic subjects did not have context information available. This is in keeping with Huppert and Piercy's previous suggestion that amnesics possess an intact item memory and a defective context memory.

\section{Wickelgren's and O'Keefe and Nadel's Theories}

The two theories of amnesia that will be discussed next have each been derived from a different model of memory. Wickelgren (1979) has proposed a memory model based on the concept of association. In Wickelgren's system, a distinction is made between what is termed "vertical" and "horizontal" associative processes. O'Keefe and Nadel (1978) have based their theory of amnesia on a memory model composed of two fundamentally different systems, a "taxon" and a "locale" system. While these two approaches to memory are quite different, they have led to assessments of the amnesic deficit that are very similar. This has occurred because the underlying dichotomy that is specified in each theory, between the two associative processes in Wickelgren's theory and between the two memory systems in O'Keefe and Nadel's theory, parallels the distinction that Huppert and Piercy (1976) make between item and context memory.

In Wickelgren's (1979) model, learning is conceptualized as the formation of associations between mental representatives of events. For instance, in the classical conditioning process, the repeated pairing of a conditioned stimulus (CS) and an unconditioned stimulus (US) may produce associations in the organism's mind between those neurons that represent the CS and those that represent the US. As a result, the presentation of the CS to the organism can activate the US neurons and consequently trigger responses mediated by the US neurons.

This process whereby associations are formed between contiguously activated neurons in the brain is what Wickelgren (1979) terms horizontal association. Hori- 
zontal associations are thought to underlie the S-R learning to which Thorndike and Hull's reinforcement theories apply, that is, S-R learning that occurs without the formation of cognitive expectancies. Thus, fish and amphibians, which are at relatively primitive stages on the scale of evolutionary development, learn by forming horizontal associations in Wickelgren's scheme.

Wickelgren (1979) suggests that the great advance in the learning abilities of birds and mammals over fish and amphibians can be attributed to the ability of these more advanced organisms to chunk. Chunking, in Wickelgren's system, is conceptualized as an association from two or more sets of neurons, each representing a different event or concept, to what will be termed here a "superordinate neuron." As a result of this "vertical" associative process, the superordinate neuron represents a set of constituent neurons. Wickelgren suggests that an ability to form these vertical associations allows birds and mammals to configure, that is, to learn to respond, in classical and instrumental conditioning, to a compound stimulus, $\mathrm{A}$ and $\mathrm{B}$, but not to each stimulus, A or B, separately.

The formation of vertical associations or chunks can be thought of as the assignment of a label to some combination of elementary concepts. This labeling capability allows for context to be encoded and thereby reduces susceptibility to interference. For example, if in a paired associate learning paradigm, the same stimulus terms are paired with new response terms in each of two lists (i.e., A-B, A-C learning), a person who learns only by forming horizontal associations will develop connections between $\mathrm{A}$ items and both $\mathrm{B}$ and $\mathrm{C}$ response terms. Consequently, once these associations have been formed, it will be difficult for the person to correctly select the response terms according to list of presentation. Thus, if asked to supply the List 2 response terms, the subject would incorrectly produce many List 1 terms. According to Wickelgren's (1979) scheme, however, if A-B and A-C pairs are differentially labeled through a vertical associative process, less interference will occur, for a subject will be capable of knowing which response terms correspond to each list.

It should be noted that the fundamental distinction between horizontal and vertical associative processes is that in vertical association, a new neuron, the superordinate neuron, is added to memory, while in horizontal association the number of neurons in memory remains unchanged. According to Wickelgren (1979), the neural mechanism underlying the vertical associative process involves the hippocampus. Specifically, Wickelgren suggests that neurons that are eligible to become superordinate neurons have weak "built-in" connections to a great number of other neurons in the cortex. One can imagine, according to this scheme, that neurons representing Events $A$ and $B$ will each be weakly connected to a number of potential superordinate neurons. At the same time, Neurons A and B might have strong horizontal associations already formed with neurons representing Events $C$ and $D$. How can the $A$ and $B$ events be chunked without $C$ and $D$ being included as well? Wickelgren proposes that the hippocampal system has diffuse excitatory connections to all potential superordinate neurons in the cortex. This allows these potential superordinate neurons to be differentially primed so that they, rather than other neurons ( $C$ and $D$ in our example), participate in the chunking process.

Disruptions of the hippocampus are proposed to seriously impair the ability to form new vertical associations. However, already existing horizontal and vertical associations can be strengthened. Thus, according to Wickelgren's (1979) theory, hippocampal damage can be expected to strongly impair performance that depends on chunking, while leaving intact the ability to do noncognitive S-R learning and learning involving the strengthening of previously established associations.

Wickelgren's (1979) proposal is consistent with most of the evidence. For example, the Winocur and Weiskrantz (1976) finding that amnesics can learn paired associates linked by some previously established semantic association (e.g., doctor-nurse) but cannot learn unrelated word pairs is in accord with Wickelgren's theory. According to Wickelgren, presentation of related words will strengthen the associations between the words that already exist; however, a defective vertical associative ability will prevent the words not already linked together in long-term memory from being labeled as belonging together. Similarly, the failure of amnesics to improve their free recall performance by forming interacting images (Baddeley \& Warrington, 1973; Cutting, 1978; but see Cermak, 1975) can be attributed to a defective vertical associative capability. The great susceptibility of amnesics to interference is also expected, since context tagging cannot be used to reduce competition from inappropriate items. On the other hand, the learning abilities that remain unimpaired in amnesics are those that, in accord with this theory, do not rely on higher level cognitive memory. For example, H.M.'s improvement on a rotary-pursuit task was the result of a sharpening of his perceptual-motor skill rather than his acquisition of an image of the wavy line whose movement he had to anticipate. A similar explanation might account for the finding that amnesics show normal learning curves on a jigsaw assembly task (D. Brooks \& Baddeley, 1976). Finally, it appears that amnesics may acquire classically conditioned responses normally (Weiskrantz \& Warrington, 1979). It is interesting to note that the two amnesic subjects in this recent study did not appear to remember any relevant details of the conditioning procedure. Thus, in accord with Wickelgren's proposals, learning apparently occurred according to an S-R rather than an expectancy mechanism.

Wickelgren's (1979) theory is also intended to account for RA, for it assumes that the hippocampal system's 
priming of potential superordinate neurons is repressed once the superordinate neurons have become associated with other neurons. This repression of excitatory hippocampal connections is suggested to take place gradually over a period of days or weeks. As a result, the susceptibility of newly formed chunks to interference will decrease continuously, for the superordinate neurons in these chunks will be progressively less likely to be primed by the hippocampal system and therefore be less likely to participate in other chunking processes. Disruptions of the hippocampal system, Wickelgren suggests, might either temporarily or permanently disrupt the functioning of the neurons to which the hippocampal system is most strongly connected. If these disruptions are temporary, both the RA and AA will be reversible; otherwise, both should be permanent.

The memory model proposed by O'Keefe and Nadel (1978) is supported by the same evidence that supports Wickelgren's (1979) theory. The theory of O'Keefe and Nadel is based on a distinction between a taxon and a locale memory system. The taxon system is analogous to semantic memory; it contains information about an item's categorical properties. The organization of this store is based on feature similarity rather than on time of encoding, and information in this taxon store is accessed on the basis of feature similarity. That is, stimulus information will activate neural elements in the taxon store that share the properties of the stimulus. Elements in the taxon system that have been activated in this way will be strengthened; however, al though strength can accumulate, the activation level of information in the taxon store will be subject to a continuous process of decay.

The locale system, which is suggested to be both constructed and stored in the hippocampus, is analogous to episodic memory. It "can be pictured as a long map extending from the past into the future, segments of which contain groups of representations in a fixed spatial (and hence temporal) relationship" (O'Keefe \& Nadel, 1978, p. 384). Information in the locale system is characterized by single-occurrence storage; that is, each stim. ulus event leaves its own independent trace. The stored information can be retrieved on the basis of the temporal or spatial characteristics of the store. Thus, time of encoding can be used as a basis for retrieval.

It should be apparent that O'Keefe and Nadel's (1978) theory encompasses Huppert and Piercy's (1976) distinction between strength and context memory. Thus, the similarity between O'Keefe and Nadel's theory and Wickelgren's (1979) theory should also be clear. It is Wickelgren's vertical associative process, the process that allows for the chunking or combining of ideas into novel configurations, that permits contextual information to be associated with already encoded information; in O'Keefe and Nadel's theory, their locale system assumes these same functions. Consequently, amnesic deficits that Wickelgren attributes to impairments in the vertical associative process, O'Keefe and Nadel can attribute to a defective locale system. For both theories, the hippocampus plays a key role in this contextual encoding process. The theories are also similar in that both allow for residual amnesic verbal long-term memory capabilities based on the strengthening of existing encodings.

The similarities between these two approaches to memory have been stressed here. There are, however, a number of differences between the theories that have a bearing on their analyses of the amnesic syndrome. For example, because O'Keefe and Nadel (1978) assume that the locale system is located in the hippocampus, their theory predicts that hippocampal damage should produce RA both for old and recent context-specific memories. Wickelgren's (1979) theory, on the other hand, assumes that RA is recency dependent. Although the experimental evidence on this question is not entirely clear, a recent review of the literature led Rozin (1976) to support the recency-dependent view of RA. The two theories also make different predictions about amnesic comprehension of semantic information. O'Keefe and Nadel argue that the deep structure of language is represented by cognitive maps in the locale system. Since, according to their theory, the hippocampus "both constructs and stores cognitive maps" (O'Keefe \& Nadel, 1978, p. 374), damage to the hippocampus should impair amnesics' comprehension. The finding that intelligence of amnesics is in the normal range is inconsistent with this position. Wickelgren's theory, on the other hand, makes no specific claims about the effect of hippocampal damage on the temporary formation of chunks, only on the long-term storage of the chunks. More will be said, in the Discussion section of this paper, about the adequacy of the context encoding deficit theories in accounting for the amnesic syndrome.

\section{DISCUSSION AND CONCLUSION}

Context deficit theories seem to provide the most satisfactory account of the amnesic memory impairment. These theories are particularly appealing because they encompass alternative approaches. Thus, as the following discussion shows, they allow the retrieval, consolidation, and semantic encoding deficit theories to be placed in perspective.

What is unique about Weiskrantz and Warrington's (1970a) partial stimulus method is that it requires little contextual information be utilized by the subject in order for his performance to appear normal. Consequently, conclusions based on this testing procedure may be misleading. Generally, tests of verbal retention allow an experimenter to determine whether the stim. ulus presentation has produced some basis on which the subject can have established an association between the experimental context and the tested item. The partial stimulus method is deceptive because it allows this association to be inferred on the basis of trace strength alone. Thus, an amnesic subject whose long- 
term learning ability has been assessed by the Weiskrantz and Warrington technique as being unimpaired would likely be incapable of remembering in any normal sense of the word. Numerous observations support this assertion. Two examples from the publications of Weiskrantz and Warrington will suffice: "Patients can identify the correct stimulus, but deny having been shown it by the experimenter" (Weiskrantz, 1966, p. 30); "when patients correctly identify an item in a cued recall task, they often are uncertain they have seen the item before; i.e., the patients do not appear to know that they are remembering" (Weiskrantz \& Warrington, 1975, p. 423). B. Milner (1970) appears to make a similar point in her comments about H.M.'s performance with incomplete pictures: "When H.M. learns to recognize these drawings with fewer and fewer cues, he is demonstrating a lowered threshold of arousal for a long-term memory rather than the acquisition of new information" (pp. 46-47). This lowered threshold, in the present view, results from the increase in the strength of an already existing trace or association. Thus, while Weiskrantz and Warrington originally argued that the partial stimulus procedure demonstrated a considerable amnesic long-term learning capability, the context deficit theories have allowed the bounds of these residual abilities to be more precisely drawn.

The context deficit theories also allow one to restrict the domain of consolidation theories. As noted earlier, the consolidation hypothesis was unable to account for the ability of hippocampal animals to show long-term retention of certain postoperatively acquired behaviors. However, according to context encoding deficit theories, one would not expect all learning to be impaired by hippocampal destruction, but instead, only that form of learning requiring contextual information. Thus, the finding that rats and monkeys are generally able to acquire an initial discrimination normally but are severely deficient in the reversed discrimination (Hirsh, 1974) can be accounted for using consolidation theory, if one restricts the consolidation deficit to the system responsible for the encoding of context.

The basic limitation of the semantic encoding deficit hypothesis of Cermak and Butters (1972) is that it restricts the amnesic deficit to semantic information. Given the admission by Cermak and his co-workers that amnesics' problem is not that they are unable to encode semantic information, but rather, that they do not spontaneously choose to do so, it is surprising that such profound memory impairments should occur. It seems more likely that the class of information that amnesics are deficient at encoding is contextual information. The tasks that Cermak and his co-workers generally use, the Brown-Peterson task, for example, require discriminations based to a large extent on temporal and other contextual information. Thus, referring to a study described previously (Cermak et al., 1974), the finding that amnesics do not show release from PI when the category of the to-be-recalled item shifts from animals to vegetables does not indicate that only semantic and not temporal information is unavailable. That is, a subject who is to make use of a "release" cue must know that this new information is appropriate to the stimulus that was most recently presented.

In choosing among the three context deficit theories of amnesia presented here, Wickelgren's (1979) theory seems best, principally because it bases the distinction between item and context memory on a memory process. An advantage of this approach, besides its making any division of memory into two types appear less arbitrary, is that it provides a basis on which predictions can be made. For example, neither Wickelgren nor O'Keefe and Nadel (1978) explicitly discuss the matter of amnesic performance with novel visual stimuli. However, since Wickelgren specifies processes by which associations are formed, one has a means for analyzing the processing of novel pictorial stimuli. Thus, one could suggest that a novel picture must still be composed of elements that are likely to be represented by established concept nodes and that exposure to the stimulus activates these nodes. Since "contiguous activation of a set of nodes strengthens the associations among all pairs of nodes in the activated set so that the subsequent activation of any one node will often be sufficient to reactivate the entire set" (Wickelgren, 1979, p. 45), the associations among a set of elementary concept nodes representing a novel picture can be strengthened. This allows one to predict that the amnesic subjects will have some residual abilities to recognize novel pictures. Furthermore, since repeated stimulus activation will gradually build up a horizontal association, amnesic performance should steadily improve as exposure to the novel picture is lengthened.

There are data that indicated Korsakoff amnesics can recognize novel pictures at above-chance levels. The study by Huppert and Piercy (1976) presented Korsakoff amnesic and alcoholic controls with 80 pictures. After 1 week, amnesics selected the correct pictures in a twoitem forced-choice test $80 \%$ of the time; control performance was $97 \%$ correct. In a subsequent study, Huppert and Piercy (1978) increased the exposure duration of pictures four to eight times longer for Korsakoff amnesics than for control subjects. This manipulation equalized recognition performance of these two groups of subjects when memory was tested $10 \mathrm{~min}, 1$ day, or 7 days after learning.

It must be pointed out that while these data conform to an analysis that can be made from Wickelgren's (1979) theory on the basis of his horizontal associative process, other explanations are possible. For instance, it is possible that amnesics recognize novel pictures on the basis of a strengthening of unrelated sets of elementary features that make up each picture. Thus, an amnesic subject may not actually be storing an integrated representation of each picture. An alternative possibility, one that seems the most likely, is that an amnesic's contextual encoding abilities may not be totally impaired. Thus, given enough processing time, 
sufficient contextual information could be stored to improve amnesic context memory.

This latter possibility will most likely frustrate many attempts to either choose between O'Keefe and Nadel's (1978) and Wickelgren's (1979) theories or to provide evidence that clearly disconfirms these theories. For example, Marslen-Wilson and Teuber (1975) found that H.M. was able to correctly identify the faces of John Glenn, Elvis Presley, and Krushchev, faces that H.M. certainly encountered only after the onset of his amnesia in 1953. Similarly, B. Milner et al. (1968) report that when H.M. was shown a Kennedy half-dollar, he correctly identified the figure on the coin as being President Kennedy. Although horizontal associations may have been involved, this encoding of novel information probably required the formation of vertical associations to, among other things, chunk the letters or phonemes that made up each public figure's name into novel configurations, and to uniquely link names and faces. Thus, these findings appear to weaken the claim that amnesics do not form vertical associations or encode context.

However, the context deficit theories of amnesia do not assert that hippocampal damage destroys the context encoding abilities completely. Consequently, the uncovering of residual context-dependent memories is not completely embarrassing to these theories. In fact, support for these context deficit theories can be based on these residual abilities. Winocur and Kinsbourne (1978), for example, have shown that amnesic recall is aided when information is learned and tested in the same unique experimental setting. In one demonstration of this, amnesic and control subjects learned a list of semantically related paired associates. After about $30 \mathrm{~min}$, the subjects learned a second list of semantically related paired associates in which List 1 stimulus words were paired with new response words. List 1 learning was conducted under unusual contextual conditions (bright red lighting, classical music playing), and List 2 learning occurred under conventional conditions (white light, no music). Although amnesics did not perform as well as controls on List 2, amnesic memory performance benefited greatly from the context shift, as evidenced by a significantly higher amnesic List 2 learning under this context-shift condition than under nonshift conditions. Winocur and Kinsbourne interpret this as purely a retrieval effect. That is, they suggest that amnesics are deficient in recreating suitable contextual cues; this deficit is minimized if the ordinarily interfering List 1 context is very different from the context suitable for List 2 retrieval. However, an account that conforms with the substantial evidence supporting context deficit theories would attribute Winocur and Kinsbourne's results to impairments in the amnesic encoding of contextual information. According to this view, the use of unique contexts for Lists 1 and 2 allows amnesic subjects to differentiate sufficiently between the two lists at retrieval only because residual encoding abilities previously allowed amnesics to form associations between list items and a small set of contextual elements in the learning environment. Because the List 1 and List 2 learning contexts were so different, minimal encoding of context was sufficient to reduce List 1 interference during List 2 retrieval. It is interesting to note, however, that while these data do conform to a context encoding deficit theory, a finding that context manipulation had no effect on amnesic recall would also be in accord with these theories. These results would be expected if one assumed that the amnesics being tested had context encoding abilities that were more completely impaired.

Two suggestions will be made for reducing the ambiguities inherent in the context deficit approaches to amnesia. First, although O'Keefe and Nadel's (1978) and Wickelgren's (1979) theories draw sharp distinctions either between basic associative processes or betweeri memory systems, these distinctions must be taken to represent extremes. Amnesic impairments must be viewed as falling along a continuum, with greater contextual encoding deficiencies being exhibited by subjects who have suffered more extensive hippocampal damage or damage to other brain structures associated with amnesia. According to this view, it can be expected that on occasions, amnesic subjects will display abilities that do not conform to a complete encoding deficit interpretation of amnesia, particularly under circumstances that do not place great demands on the contextual encoding apparatus. This approach allows such findings as those of Cermak (1975) to be placed into perspective. Cermak demonstrated that instructions to form interacting images did aid amnesic retrieval. This, of course, contradicts the assertion that amnesics are unable to form new vertical associations to link already existing long-term memory concepts (i.e., to chunk). Cermak's results also contradict the findings of Baddeley and Warrington (1973), which showed amnesic subjects did not benefit from imagery instructions. The apparent contradiction between these two sets of results is lessened, however, when one considers the circumstances under which Cermak demonstrated the beneficial effects of imagery on amnesic performance: Unlike Baddeley and Warrington's study, which required subjects to link four words together within 16 four-word sets, Cermak's subjects were presented lists made up of only five word pairs.

A second suggestion is that more effort be made to assess the degree to which amnesic subjects serving in memory experiments are impaired. The context encoding deficit theories would be strengthened by a demonstration of correlations between performance on tasks that depended on context encoding (chunking) abilities. For example, it would be expected, according to context deficit theories, that an amnesic's ability to benefit from List 2 learning done in a unique experimental setting would correlate with ability to benefit from imagery formation during paired associate learning.

Although it is convenient to build models of memory on sharply differentiated processes or stores, there is 
evidence that amnesics may have general processing deficits not easily attributable to a dysfunction of one of these memory stores or processes. Oscar-Berman, Goodglass, and Cherlow (1973) found that the perception thresholds of Korsakoff subjects were significantly higher than those of controls: The stimulus-exposure duration needed by Korsakoff patients to identify words and patterns was three to four times that needed by control subjects. Cermak et al. (1974) showed that in a letter-matching task, amnesic Korsakoff patients took $140-290 \mathrm{msec}$ longer than alcoholic subjects to judge the physical and name identities of letter pairs. It has been demonstrated that amnesics have a slower than normal search rate of both short-term memory (Naus, Cermak, \& DeLuca, 1977) and "conceptual" semantic memory (Cermak, Reale, \& Baker, 1978). And Glosser, Butters, and Samuels (1976) found that Korsakoff amnesics were impaired relative to alcoholic controls in detecting the occurrence of a particular pair of dichotically presented digits, but not in detecting the occurrence of a single digit in either ear. If evidence of such general processing deficits in amnesics continues to accumulate, it may become more parsimonious to adopt a view that has been suggested by Spear (1978), who likens the symptoms of amnesia to those that are manifested "when the central nervous system is less than optimal in its functioning" (p.303). It may be that under these conditions, the abilities that underlie the encoding of context-which result from the most recent evolutionary developments of the memory system and are possibly the most sensitive to disruption (Rozin, 1976)-are the most strongly impaired.

\section{REFERENCES}

Baddeley, A. D., \& Warrington, E. K. Amnesia and the distinction between long- and short-term memory. Journal of Verbal Learning and Verbal Behavior, 1970, 9, 176-189.

Baddeley, A. D., \& Warrington, E. K. Memory coding and amnesia. Neuropsychologia, 1973, 11, 159-165.

Brooks, D. N., \& BAdDELEY, A. D. What can amnesic patients learn? Neuropsychologia, 1976, 14, 111-122.

Brooks, L. R. Spatial and verbal components of the act of recall. Canadian Journal of Psychology, 1968, 22, 349-368.

Butters, N., \& Cermak, L. S. Some comments on Warrington and Baddeley's report of normal short-term memory in amnesic patients. Neuropsychologia, 1974, 12, 283-285.

Butters, N., \& Cermak, L. S. Some analyses of amnesic syndromes in brain-damaged patients. In R. L. Isaacson \& K. H. Pribram (Eds.), The hippocampus. New York: Plenum, 1975.

Butters, N., Lewis, R., Cermak, L. S., \& Goodglass, H. Material-specific memory deficits in alcoholic Korsakoff patients. Neuropsychologia, 1973, 11, 291-299.

Cermak, L. S. Imagery as an aid to retrieval for Korsakoff patients. Cortex, 1975, 11, 163-169.

Cermak, L. S., \& Butters, N. The role of interference and encoding in the short-term memory deficits of Korsakoff patients. Neuropsychologia, 1972, 10, 89-95.

Cermak, L. S., \& Butters, N. Information processing deficits of alcoholic Korsakoff patients. Quarterly Journal of Studies on Alcohol, 1973, 34, 1110-1132.
Cermak, L. S., Butters, N., \& Gerrein, J. The extent of the verbal encoding ability of Korsakoff patients. Neuropsychologia, $1973,11,85-94$.

Cermak, L. S., Butters, N., \& Goodglass, H. The extent of memory loss in Korsakoff patients. Neuropsychologia, 1971 9, 307-315.

Cermak, L. S., Butters, N., \& Moreines, J. Some analyses of the verbal encoding deficit of alcoholic Korsakoff patients. Brain and Language, 1974, 2, 141-150.

Cermak, L. S., Reale, L., \& Baker, E. Alcoholic Korsakoff patients' retrieval from semantic memory. Brain and Language, $1978,5,215-226$

Corkin, S. Acquisition of motor skill after bilateral medial temporal-lobe excision. Neuropsychologia, 1968, 6, 255-266.

Craik, F. I. M., \& Lockhart, R. S. Levels of processing: A framework for memory research. Journal of Verbal Learning and Verbal Behavior, 1972, 11, 671-684.

Craik, F. I. M., \& Tulving, E. Depth of processing and the retention of words in episodic memory. Journal of Experimental Psychology: General, 1975, 104, 268-294.

Craik, F. I. M., \& Watkins, M. J. The role of rehearsal in short-term memory. Journal of Verbal Learning and Verbal Behavior, 1973, 12, 599-607.

Cutring, J. A cognitive approach to Korsakoff's syndrome. Cortex, 1978, 14, 485-495.

Deutsch, J. A., \& Deutsch, D. Physiological psychology. Homewood, Ill: Dorsey, 1966.

Dillon, R. F., \& REID, L. S. Short-term memory as a function of information processing during the retention interval. Journal of Experimental Psychology, 1969, 81, 261-269.

Drachman, D. A., \& Arbit, J. Memory and the hippocampal complex 11. Is memory a multiple process? Archives of Neurology, 1966, 15, 52-61.

Duncan, D. P. The retroactive effect of electroshock on learning. Journal of Comparative and Physiological Psychology, 1949, $42,32-44$.

Glosser, G., Butters, N., \& Samuels, I. Failures in information processing in patients with Korsakoff's syndrome. Neuropsychologia, 1976, 14, 327-334.

Hirsh, R. The hippocampus and contextual retrieval of information from memory: A theory. Behavioral Biology, 1974, $12,421-444$

Horel, J. A. The neuroanatomy of amnesia: A critique of the hippocampal memory hypothesis. Brain, 1978, 101, 403-445.

Huppert, F. A., \& Piercy, M. Recognition memory in amnesic patients: Effect of temporal context and familiarity of material. Cortex, 1976, 4, 3-20.

Huppert, F. A., \& Piency, M. The role of trace strength in recency and frequency judgments by amnesic and control subjects. Quarterly Journal of Experimental Psychology, 1978, 30, 347-354.

IsAACson, R. L. Hippocampal destruction in man and other animals. Neuropsychologia, 1972, 10, 47-64.

Kimale, D. P. Choice behavior in rats with hippocampal lesions In R. L. Isaacson \& K. H. Pribram (Eds.), The hippocampus. New York: Plenum, 1975.

Kinsbourne, M., \& Wood, F. Short-term memory and the amnesic syndrome. In D. Deutsch \& J. A. Deutsch (Eds.), Short-term memory. New York: Academic Press, 1975.

LEwis, D. J. Sources of experimental amnesia. Psychological Review, $1969,5,461-472$

Lewis, D. J., \& MAHer, B. A. Neural consolidation and electroconvulsive shock. Psychological Review, 1965, 72, 225-239.

Lewis, D. J., Misanin, J. R., \& Millek, R. R. Recovery of memory following amnesia. Nature, 1968, 220, 704-705.

Marslen-Wilson, W. D., \& Teuber, H. Memory for remote events in anterograde amnesia: Recognition of public figures from newsphotographs. Neuropsychologia, 1975, 13, 353-364.

MarTIN, M. Memory span as a measure of individual differences in memory capacity. Memory \& Cognition, 1978, 6, 194-198. Mattis, S., \& Kovner, R. Different patterns of mnemonic 
deficits in two organic amnestic syndromes. Brain and Language, 1978, 6, 179-191.

McGEOCH, J. A. The psychology of human learning. New York: Longmans, Green, 1942.

Milner, B. Memory disturbances after bilateral hippocampal lesions. In P. Milner \& S. Glickman (Eds.), Cognitive processes and the brain. New York: Van Nostrand, 1965.

Milner. B. Amnesia following operation on the temporal lobes. In C. W. Whitty \& O. L. Zangwill (Eds.), Amnesia. London: Butterworths, 1966.

Milner, B. Disorders of memory after brain lesions in man. Preface: Material-specific and generalized memory loss. Neuropsychologia, 1968, 6, 175-179.

Milner, B. Memory and the medial temporal regions of the brain. In K. H. Pribram \& D. E. Broadbent (Eds.), Biology of memory. New York: Academic Press, 1970.

Milner, B., Corkin, S., \& Teuber, H. L. Further analysis of the hippocampal amnesic syndrome; 14-year follow-up study of H. M. Neuropsychologia, 1968, 6, 215-234.

Milner, B., \& Teuber, H. L. Alteration of perception and memory in man: Reflections on methods. In L. Weiskrantz (Eds.), Analysis of behavioral change. New York: Harper \& Row, 1968

Milner, P. M. Physiological psychology. San Francisco: Holt, Rinehart, \& Winston, 1970.

Müller, G. E., \& Pilzecker, A. Experimentalle Beitrage zur Lehre vom Gedachtnis. Zeitschrift fur Psychologie, 1900, 1, $1-300$.

Naus, M. J., Cermak, L. S., \& DeLuca, D. Retrieval processes in alcoholic Korsakoff patients. Neuropsychologia, 1977, 15, 737.742.

O'KeFfe, J., \& NADEL, L. The hippocampus as a cognitive map. New York: Oxford University Press, 1978.

Orbach, J., Milner, B., \& Rasmussen, T. Learning and retention in monkeys after amygdala-hippocampus resection. Archives of Neurology, Chicago, 1960, 3, 230-251.

Oscar-Berman, M., Goodglass, H., \& Cherlow, D. G. Perceptual laterality and iconic recognition of visual materials by Korsakoff patients and normal adults. Journal of Comparative and Physiological Psychology, 1973, 82, 216-231.

Peterson, L. R. Short-term verbal memory and learning. Psychological Review, 1966, 73, 193-207.

Rozin, P. The psychobiological approach to human memory In M. R. Rosenzweig \& E. L. Bennett (Eds.), Neural mechanisms of learning and memory. Cambridge, Mass: M.I.T. Press, 1976.

Russell, W. R., \& Nathan, P. Traumatic amnesia. Brain, $1946,69,280-300$.

SCOville, W. B., \& Milner, B. Loss of recent memory after bilateral hippocampal lesions. Journal of Neurology, Neurosurgery, and Psychiatry, 1957, 20, 11-21.

Sidman, M., Stoddard, L. T., \& Mohr, J. P. Some additional quantitative observations of immediate memory in a patient with bilateral hippocampal lesions. Neuropsychologia, 1968, 6, 245-254.

Spear, N. E. The processing of memories: Forgetting and retention. New York: Wiley, 1978.

Strauss, E. H., \& Butler, R. B. The effect of varying types of interference on haptic memory in the Korsakoff patient. Neuropsychologia, 1978, 16, 81-90.

TAlland, G. A. Deranged memory. New York: Academic Press, 1965.

Thompson, R., \& Dean, W. A further study of the retroactive effect of ECS. Journal of Comparative and Physiological Psychology, 1955, 48, 488-491.

Tulving, E. Theoretical issues in free recall. In T. R. Dixon \&
D. L. Horton (Eds.), Verbal behavior and general behavior theory. Englewood Cliffs, N.J: Prentice-Hall, 1968.

Warrington, E. K. Deficient recognition memory in organic amnesia. Cortex, 1974, 10, 289-291.

Warhington, E. K., \& Sanders, H. I. The fate of old memories. Quarterly Journal of Experimental Psychology, 1971, 23, 432-442.

Warrington, E. K., \& Weiskrantz, L. A new method of testing long-term retention with special reference to amnesic patients. Nature, 1968, 217, 972-974.

Warrington, E. K., \& Weiskrantz, L. Amnesic syndrome: Consolidation or retrieval? Nature, 1970, 228, 628-630.

Warrington, E. K., \& Weiskrantz, L. Organizational aspects of memory in amnesic patients. Neuropsychologia, 1971, 9, 67.73.

Warrington, E. K., \& Weiskrantz, L. An analysis of shortterm and long-term memory defects in man. In J. A. Deutsch (Ed.), The physiological basis of memory. New York: Academic Press, 1973.

Warrington, E. K., \& Weiskrantz, L. The effect of prior learning on subsequent retention in amnesic patients. Neuropsychologia, 1974, 12, 419-428.

Warrington, E. K.. \& Weiskrantz, L. Further analysis of the prior learning effect in amnesic patients. Neuropsychologia, $1978,16,169-177$.

Watkins, M. J., \& Watkins, O. C. Processing of recency items for free recall, Journal of Experimental Psychology, 1974, 102, 488-493.

WEISKRANTZ, L. Experimental studies of amnesia. In C. M. Whitty \& O. L. Zangwill (Eds.), Amnesia. London: Butterworths, 1966.

WEISKRanTz, L. Trying to bridge some neuropsychological gaps between monkey and man. British Journal of Psychology, 1977, 68, 281-288.

WEISKrantz, L., \& Warrington, E. K. A study of forgetting in amnesic patients. Neuropsychologia, 1970, 8, 281-288. (a)

Weiskrantz, L., \& Warrington, E. K. Verbal learning and retention by amnesic patients using partial information. Psychonomic Science, 1970, 20, 210-211. (b)

Weiskrantz, L., \& Warrington, E. K. The problem of the amnesic syndrome in man and animals. In R. L. Isaacson \& K. H. Pribram (Eds.), The hippocampus. New York: Plenum, 1975.

Weiskrantz, L., \& Warrington, E. K. Conditioning in amnesic patients. Neuropsychologia, 1979, 17, 187-194.

Wickelgren, W. A. Sparing of short-term memory in an amnesic patient: Implications for a strength theory of memory. Neuropsychologia, 1968, 6, 235-244.

Wickelgren, W. A. The long and short of memory. Psychological Bulletin, 1973, 80, 425-438.

Wickelghen, W. A. Chunking and consolidation: A theoretical synthesis of semantic networks, configuring in conditioning, S-R versus cognitive learning, normal forgetting, the amnesic syndrome and the hippocampal arousal system. Psychological Review, 1979, 86, 44-60.

Williams, M. Investigation of amnesic defects by progressive prompting. Journal of Neurology, Neurosurgery and Psychiatry, $1953,16,14-18$.

Winocur, G., \& Kinsbourne, M. Contextual cueing as an aid to Korsakoff amnesics. Neuropsychologia, 1978, 16, 671-682.

Winocur, G., \& Weiskrantz, L. An investigation of pairedassociate learning in amnesic patients. Neuropsychologia, 1976, 14, 97-110.

(Received for publication August 14, 1980; revision accepted November 17,1980 .) 